\title{
Prediction of sexual function following spinal cord injury: a case series
}

\author{
J.G. Previnaire ${ }^{1}$ J.M. Soler ${ }^{2}$ M.S. Alexander ${ }^{3,4,5} \cdot$ F. Courtois $^{6} \cdot$ S. Elliott $^{7} \cdot$ A. McLain $^{3}$
}

Received: 25 July 2017 / Revised: 2 October 2017 / Accepted: 4 October 2017

(C) International Spinal Cord Society 2017

\begin{abstract}
Introduction Spinal Cord Injury (SCI) affects sexual response based on the level and degree of completeness of injury. By using the International Standards for the Neurologic Classification of SCI in conjunction with lumbo-sacral reflexes these effects can be predicted. The International Standards for the Assessment of Autonomic Function after SCI (ISAFSCI) document the impact of SCI on sexual responses including psychogenic and reflex arousal (erection or lubrication), orgasm, ejaculation, and sensation of menses. Responses are described based upon a 0 to 2 scale with 0 being absent, 1 altered, and 2 normal response. Additionally, the lesion is described as supraconal, conal or infraconal.
\end{abstract}

Case presentation We present 4 representative cases of the impact of SCI on sexual responses and course of treatment. Case 1 describes a complete supraconal lesion above T6 with upper motor neuron syndrome. Case 2 describes a supraconal complete lesion including the T11-L2 segment. Case 3 describes an infraconal (cauda equina) lesion with lower motor neuron syndrome. Case 4 is theoretical and describes a supraconal lesion above T6 with upper motor neuron syndrome, partial sensation in T11-L2 dermatomes, and other medical comorbidities.

Discussion Neurologic examination combined with reflex testing allows prediction of sexual responses after SCI. It would be useful for version 2.0 of the ISAFSCI to assist clinicians in determining the anticipated changes, whether their patients are functioning as anticipated sexually after SCI or whether other concerns also require treatment.

\section{Introduction}

Sexuality is an important part of life. Spinal cord injury (SCI) results in alterations in physiological sexual responses and negatively impacts sexual interest and satisfaction. SCIs are usually located in discrete areas of the neuraxis, and, based upon which descending spinal motor and autonomic pathways are disrupted, can result in predictable impacts on sexual function. Three spinal segments are of particular importance for sexual function: the T11-L2 sympathetic, the S2-S4 parasympathetic, and the somatic centers [1-3]. Depending on the level and the severity of injury to these pathways, alterations in genital sexual arousal (including erection in males and lubrication in females) occur [4-6]. Additionally, alterations in the ability to achieve ejaculation and orgasm can be considered in relation to altered

J.G. Previnaire

previnjg@hopale.com

Extended author information available on the last page of the article supraspinal control of the sympathetic and parasympathetic nervous systems $[5,7,8]$.

The Neurological Classification of Spinal Cord Injury (ISNCSCI) was developed to classify SCI [9]. It rates impairment of motor and sensory function but not autonomic function. To fill this gap, the International Standards for the Assessment of Autonomic Function after SCI (ISAFSCI) were developed to evaluate and describe remaining autonomic function [8]. Based on the ISAFSCI, it is recommended that autonomic function is routinely evaluated in individuals with SCI [8, 10]: general autonomic function (control of the heart, blood pressure, sweating, temperature, broncho-pumonary system), lower urinary tract, bowel and sexual function, and urodynamic evaluation. In regards to sexual responses, the autonomic standards rate different aspects including psychogenic and reflex genital arousal (erection or lubrication), orgasm, ejaculation (in men), and sensation of menses (in women) on a 3-point scale: normal function [2], reduced or altered function [1], and complete loss of function (0). Anatomical diagnosis is used to distinguish between supraconal, conal, and cauda equina lesions. 
Table 1 Specific somatic reflexes related to sexual function

\begin{tabular}{|c|c|c|c|}
\hline Reflexes & $\begin{array}{l}\text { Spinal } \\
\text { segment }\end{array}$ & Stimulation & Action \\
\hline Anal wink & S2-S3-S4 & Noxious or tactile stimulation of the perineal skin & $\begin{array}{l}\text { Contraction of external anal } \\
\text { sphincter }\end{array}$ \\
\hline Bulbocavernosus & S2-S3-S4 & Squeeze the glans penis or clitoris & $\begin{array}{l}\text { Contraction of bulbocavernosus } \\
\text { muscle }\end{array}$ \\
\hline Adductor & L1-L2-L3 & Strike the adductor tendon (rubber hammer) & Contraction of adductor muscle \\
\hline Cremaster & T12-L1-L2 & Strike the medial aspect of the proximal thigh & Brisk elevation of ipsilateral testicle \\
\hline $\begin{array}{l}\text { Abdominal above umbilicus } \\
\text { below umbilicus }\end{array}$ & $\begin{array}{l}\text { T6-T10 } \\
\text { T10-T12 }\end{array}$ & $\begin{array}{l}\text { Gentle stroke of the skin, or direct stroke on abdominal } \\
\text { muscle (rubber hammer) }\end{array}$ & $\begin{array}{l}\text { Contractions of corresponding } \\
\text { abdominal muscle(s) }\end{array}$ \\
\hline
\end{tabular}

Bold: the most implicated spinal segment

The ISAFSCI are designed to facilitate communication amongst clinicians and researchers by providing a simple way to describe the impact of injury on sexual responses. Through performance of a comprehensive physical examination including the ISNCSCI in conjunction with the sexual function component of the ISAFSCI and determination of specific reflexes as detailed in Table 1, the probable and/or likely impact of injury on sexual responses can be determined. Specific autonomic reflexes related to sexual function are outlined in Table 2. The goal of this paper is to present a series of clinical cases describing the impact of injury on sexual responses through utilization of the ISAFSCI and to describe a situation where the person's actual status differed from the expectations based upon the ISAFSCI and to describe a pathway for treatment.

\section{Methods}

The ISAFSCI was applied during the regular patients' treatment as part of the clinical routine. A combination of actual and educational case reports were proposed by author and coauthors, out of which the 4 most representative cases were selected. All patients gave their informed consent.

\section{Case presentation}

\section{Case report 1}

JR is a 24-year-old gentleman, who sustained a traumatic SCI 1 year ago. He was independent in a manual wheelchair, played tennis, and had a girlfriend. He had no sexual problems prior to injury and was previously healthy. $\mathrm{He}$ complained of poor satisfaction with his sexual life. He reported his libido was normal, and reflex erections were of good quality but did not last long enough to allow penetration. He did not have psychogenic erection, ejaculation, or orgasm
With re gards to bladder function, he was on intermittent catheterization 5 times daily. He had previously been diagnosed with detrusor hyperactivity with sphincter dyssynergia. This was ineffectively controlled by anticholinergics, and a botulinum toxin injection 2 months prior resolved this issue. His bowel routine consisted of alternate day bowel program using a suppository. Medications included baclofen $20 \mathrm{mg}$ tid and pregabalin $75 \mathrm{mg}$ bid.

Physical examination revealed T5 AIS A paraplegia with a complete absence of sensation to pinprick and light touch below the level of injury, and moderate spasticity in the legs with spasms of the abdominal muscles. Sacral reflexes (bulbocavernosus and anal wink) and thoracolumbar T11L2 reflexes (dartos, cremaster) were present. Vasomotor reflexes on the thorax showed a T7 autonomic level of lesion and pilomotor and sudomotor reflexes were found on both legs. The initial ISAFSCI classification was supraconal, psychogenic erection 0 , reflex erection 1 , ejaculation 0 , and orgasm 0 .

For erectile dysfunction, JR was managed with oral sildenafil $50 \mathrm{mg} 1-2 \mathrm{~h}$ prior to sexual activity. This was very effective, allowing sexual intercourse with penetration and greater satisfaction in sexual life, but he still reported no ejaculation or orgasmic sensation.

With regards to ejaculatory dysfunction, in the clinic setting JR did not respond to penile vibratory stimulation (PVS) alone, but had success with the combination of the sympathomimetic midodrine $15 \mathrm{mg} 1 \mathrm{~h}$ prior to the PVS. This resulted in strong autonomic signs, with dartos contraction and pilomotor reflexes on both legs. His systolic blood pressure did increase to $170 \mathrm{~mm} \mathrm{Hg}$ with the combination of midodrine plus PVS but resolved spontaneously after ejaculation. He also reported mild orgasmic sensations and inhibition of spasticity for about $1 \mathrm{~h}$ afterwards.

Despite the positive responses in the clinic, JR was frustrated at home because ejaculation and orgasm were not present during his sexual activities. This was resolved by adding vibratory stimulation at home at the end of sexual intercourse which resulted in a more satisfactory sexual life. 
Table 2 Specific autonomic reflexes related to sexual function

\begin{tabular}{llll}
\hline Reflexes & $\begin{array}{l}\text { Spinal } \\
\text { segment }\end{array}$ & Stimulation & Action \\
\hline Dartos & T10-L2 & Local cold & $\begin{array}{l}\text { Ipsilateral wrinkling of the scrotum and elevation of } \\
\text { the testis }\end{array}$ \\
$\begin{array}{l}\text { Sudomotor \& pilomotor } \\
\text { Vasomotor (skin axon- } \\
\text { reflex) }\end{array}$ & T3-T12 & $\begin{array}{l}\text { Pressor stimuli below the lesion (bladder filling, } \\
\text { PVS } \ldots \text { Sweating \& goose bumps on legs } \\
\text { Mechanical stimulation of the skin }\end{array}$ & $\begin{array}{l}\text { Flush above the lesion, vasoconstriction at and below } \\
\text { the lesion }\end{array}$ \\
\hline
\end{tabular}

$P V S$ penile vibratory stimulation

The ISAFSCI sexual function classification after therapeutic intervention would be supraconal, psychogenic erection 0 , reflex erection 1 , ejaculation 1 , and orgasm 1 .

\section{Case report 2}

BD is a 28-year-old gentleman who sustained a traumatic SCI 1 year ago. BD was independent in his wheelchair and had been married for 2 years. He had no sexual problems prior to injury and was otherwise healthy.

He reported strong libido. He had reflex erections but they did not last long enough to allow for sexual intercourse. He reported absence of psychogenic erection, ejaculation, or orgasmic sensation.

His bladder was managed with intermittent catheterization 5 times a day. He used anticholinergics to prevent leakage, but leakage occurred during transfers, and retrograde cystography showed an open bladder neck. His bowel program consisted of digital removal of feces every other day. Medications included oxybutynin chloride $5 \mathrm{mg}$ tid and oral psyllium $2.6 \mathrm{~g}$ bid.

Physical examination revealed T10 AIS A paraplegia with no sensation below the level of injury and moderate spasticity in the legs. Sacral reflexes (bulbocavernosus and anal wink) were present. Thoracolumbar reflexes (dartos, cremaster) were absent. Vasomotor reflexes on the thorax showed a T7 autonomic level of lesion. Pilomotor and sudomotor reflexes were absent in the legs. Initial ISAFSCI was supraconal, psychogenic erection 0 , reflex erection 1 , ejaculation 0 , orgasm 0 .

The patient was treated with oral tadalafil $20 \mathrm{mg}$ for his erectile dysfunction. He was unable to achieve ejaculation or genital orgasm in laboratory setting despite use of PVS with midodrine up to $30 \mathrm{mg}$. His autonomic classification after therapeutic intervention was unchanged.

\section{Case report 3}

FC is a 22-year-old gentleman, who sustained a traumatic SCI secondary to L1 vertebral fracture 22 months previously. He was homosexual and single and fully independent in a manual wheelchair. He had no sexual problems prior to injury and was otherwise healthy. He was not on any medications. The patient was very unhappy with his sex life and complained of inability to have erections adequate for penetration, ejaculation, or orgasm. He also reported emission of semen during non-sexual activities.

With regards to other sacral function, he had been on intermittent catheterization 5 times a day without any leakage. Urodynamics showed detrusor hypoactivity. He complained of severe constipation with difficulty with stool extraction. After failure of other modalities, transanal irrigation was started with good results.

Physical examination revealed L4 AIS A flaccid paraplegia. Sacral reflexes were absent and thoracolumbar reflexes were present. There was sensation at the testis and epididymis and pilomotor and sudomotor reflexes were absent. ISAFSCI classification was infraconal, psychogenic erection 1 , reflex erection 0 , ejaculation 0 , orgasm 0 .

FC had psychogenic erections but they did not allow penetration. Phosphodiesterase inhibitors were ineffective. Intracavernous injections of prostaglandin E1 were effective at a dose of $30 \mathrm{ug}$ but duration of erection was limited to 10 min. The patient was also noted to have absence of ejaculation during masturbation and he failed to ejaculate with PVS alone or in conjunction with midodrine up to $30 \mathrm{mg}$. The patient was unable to achieve orgasm. ISAFSCI classification after therapeutic intervention remained unchanged.

\section{Case report 4}

AE is a 43-year-old female who sustained a T7 AIS B SCI in a skiing accident 9 years earlier. She was married and had 2 children prior to her injury. Prior to her injury, she had no sexual concerns. She was regularly sexually active with her husband and routinely had orgasms. She presented to clinic complaining of decreased sexual function for the past year. While she had initially achieved orgasm post injury and had adequate lubrication, over the past year she noted an inability to achieve orgasm, despite attempting vibratory stimulation in conjunction with her usual pattern of sex with 
her husband. She had tried masturbating and at present did not think she had psychogenic or reflex lubrication. She complained of anxiety and inability to relax during sexual activity due to these issues. She was continent with intermittent catheterization 5 times daily and was on a daily morning bowel program.

Functionally, she was independent in activities of daily living and wheelchair mobility.

Past medical history was remarkable for a long-standing history of depression with chronic use of duloxetine. Two years ago, she was started on propranolol for hypertension and a year prior she was switched to fluoxetine from duloxetine. Over the past few months her periods have started to become irregular.

Medications included baclofen $20 \mathrm{mg}$ qid, Prozac $20 \mathrm{mg}$ daily, Colace $100 \mathrm{mg}$ bid, senekot 2 tabs po at bedtime, and propranolol $20 \mathrm{mg}$ po tid.

Physical examination revealed blood pressure $88 / 58$, HR 57, resp 20.

Neurologic examination revealed sensation intact to T7 bilaterally to pin and light touch, grade 2 light touch was present to T12 bilaterally and grade 1 light touch was present below this level through S5 bilaterally. Pinprick sensation was grade 2 to T7 bilaterally, grade 1 to pinprick to T12 bilaterally and absent below. Anal exam revealed no voluntary contraction, intact sensation at the anal sphincter, and positive bulbocavernosus reflex.

Clinical course: Upon review of the AE's physical examination it was determined that solely based upon her SCI she would likely be able to have psychogenic arousal due to the significant retention of sensation in the T11-L2 dermatomes and reflex arousal due to the presence of the bulbocavernosus reflex. Additionally, it was determined that she should have neurologic potential for orgasm. Her original situation would be reported via ISAFSCI as psychogenic arousal 1, reflex arousal 2, orgasm 2, and menses 2 . However, based upon her recent changes in function, using the ISAFSCI AE would be described as psychogenic arousal 0 , reflex arousal 0 , orgasm 0 , and menses 1 .

It was determined the medications $\mathrm{AE}$ was taking likely contributed to her sexual dysfunction. Therefore, she was weaned down on the fluoxetine to $10 \mathrm{mg}$ daily for 4 weeks and then it was discontinued. She was also decreased on the propanolol to $20 \mathrm{mg}$ bid and her baclofen was decreased to $20 \mathrm{mg}$ tid. She was provided supportive counseling and masturbation was recommended with a goal to resuming a mindful approach to sexuality.

AE returned for a follow-up 6 weeks later. She reported she had masturbated weekly during the past month and that she had started using lubricant and noticed an increase in arousal. At this point her HR was 72 and her BP was 96/64. She felt a bit irritable but thought it was tolerable and did not want to resume taking an antidepressant. AE had not noted any spasms, and her blood pressure readings were reasonable. She was switched to baclofen $10 \mathrm{mg}$ three times daily and her propanolol was decreased to $20 \mathrm{mg}$ by mouth at bedtime for two weeks and then discontinued. She was told that her sexual function would continue to improve and to return in 6 weeks.

Upon return to clinic, she reported that she had regained the capacity for orgasm. Her spasms were a bit stronger but tolerant and she remained independent in activities of daily living. Her periods remained irregular. Blood pressure was 105/70 and HR was 74. Ashworth scale was unchanged. At this point it was suggested that she could consider further decrease in the baclofen dose, and she opted for a decrease in the dose to $10 \mathrm{bid}$ and the option to take an additional 10 $\mathrm{mg}$ as needed.

Six months later she was doing well. Her periods had stopped and she had occasional hot flashes but these were tolerable. Her sexual life was satisfactory and she regularly used lubrication. She was taking her baclofen at a dose of $10 \mathrm{mg}$ bid and increasing as needed to $30 \mathrm{mg}$ daily. ISAFSCI classification after therapeutic intervention was psychogenic 1 , reflex 2 , orgasm 2 , menses 0 .

\section{Summary of cases}

These cases illustrate several points regarding SCI and sexual concerns. In persons with SCI it is useful to supplement the examination with thoracolumbar reflex testing which may also provide information about ejaculation in males. These reflexes are described in Tables 1 and 2 .

Table 3 summarizes the findings in all four cases. Cases 1 and 2 are representative of men with a supraconal lesion above T10, and UMN syndrome. In these situations, based solely upon the injury, reflex sexual arousal (erection) will occur, projectile ejaculation, and orgasm are possible. The presence of psychogenic sexual arousal has been linked to retention of preservation of T11-L2 sensation. Orgasmic function has been shown to occur in complete patients with preservation of an active $\mathrm{BC}$ reflex or in incomplete injury patients with preservation of motor and/or sensory function in the S3-5 segments. Therapeutic interventions allowed improvement of sexual life in case 1, but not in case 2 .

In case of infraconal (cauda equina) lesion with LMN syndrome, psychogenic sexual arousal is possible, reflex arousal is not. In men, this often results in erection of poor quality with only dribbling emission. With complete LMN lesion to the sacral segments genital orgasm is usually not present in either men or women. Therapeutic interventions are usually less effective in situations like these, and failed to help this man.

Case 4 is representative of women with supraconal lesion above T10, and UMN syndrome, and partial sensation in T11-L2 dermatomes. In this situation, reflex arousal will 
Table 3 Summary of the case reports

\begin{tabular}{|c|c|c|c|c|c|c|c|c|c|c|c|c|c|c|}
\hline & \multirow[t]{2}{*}{ Gender } & \multirow[t]{2}{*}{ NLI } & \multirow[t]{2}{*}{ Type } & \multirow{2}{*}{$\begin{array}{l}\text { T11- } \\
\text { L2 }\end{array}$} & \multicolumn{5}{|c|}{ ISAFSCI before interventions } & \multicolumn{5}{|c|}{ ISAFSCI after interventions } \\
\hline & & & & & $\begin{array}{l}\text { Psychogenic } \\
\text { arousal }\end{array}$ & $\begin{array}{l}\text { Reflex } \\
\text { arousal }\end{array}$ & Ejaculation & Orgasm & Menses & $\begin{array}{l}\text { Psychogenic } \\
\text { arousal }\end{array}$ & $\begin{array}{l}\text { Reflex } \\
\text { arousal }\end{array}$ & Ejaculation & Orgasm & Menses \\
\hline Case 1 & Male & $\begin{array}{l}\text { T6 AIS } \\
\text { A }\end{array}$ & UMN & absent & 0 & 1 & 0 & 0 & - & 0 & 1 & 1 & 1 & - \\
\hline Case 2 & Male & $\begin{array}{l}\text { T10 } \\
\text { AIS A }\end{array}$ & UMN & absent & 0 & 1 & 0 & 0 & - & 0 & 1 & 0 & 0 & - \\
\hline Case 3 & Male & $\begin{array}{l}\text { L4 AIS } \\
\text { A }\end{array}$ & $\mathrm{LMN}$ & Present & 1 & 0 & 0 & 0 & - & 1 & 0 & 0 & 0 & - \\
\hline Case 4 & Female & $\begin{array}{l}\text { T7 AIS } \\
\text { B }\end{array}$ & UMN & Present & 0 & 0 & - & 0 & 0 & 1 & 2 & - & 2 & 1 \\
\hline
\end{tabular}

ISAFSCI International Standards for the Assessment of Autonomic Function after SCI, UMN upper motor neuron, LMN lower motor neuron, $P V S$ penile vibratory stimulation

occur, psychogenic arousal (lubrication) will be related to the degree of sensory preservation in the T11-L2 dermatomes and orgasm is possible. Therapeutic interventions are possible, and considerably helped in this case. Case 4 also documents change in sexual function due to aging and medications. The woman's perimenopausal status caused irregularities in her periods and likely alterations in lubrication. Baclofen, propanolol, and fluoxetine may cause sexual dysfunction, and negatively impact sexual responses. This dysfunction compounded her stress during sexual activity and the inability to focus on pleasurable sensations. Remaining neurologic function in the T11-L2 area is indicative of positive potential for psychogenic arousal, but can also negatively impact on sexual response if a person is thinking about other things during sexual activity.

\section{Discussion}

As described above, the prediction of sexual function following SCI requires a comprehensive neurological clinical examination, including assessment of both somatic and autonomic function of the segments concerned.

The integrity or reflex function of two spinal segments is essential for sexual function [1-3, 11]. The T11-L2 sympathetic center is the lowest part of the sympathetic spinal center. Here the cell bodies that are responsible for psychogenic sexual arousal (psychogenic erection in men, and genital vasocongestion in women) and emission of semen in men lie in the intermediolateral cell columns with impulses to the end organs traveling through fibers of the hypogastric nerves. The S2-S4 parasympathetic center mediates reflex sexual arousal through fibers of the pelvic nerve and the S2-S4 somatic center and along with fibers of the pudendal nerve supplies the striated muscles of the pelvic floor. It is responsible for involuntary rhythmic contractions during orgasm and projectile ejaculation in men.

Assessment of autonomic function is often daunting for clinicians. Batteries of tests have been described to help assess different components of each system. However, these tests are often unavailable in the clinical setting and many are time consuming $[12,13]$. The tests listed in Table 2 can easily be performed at the patient's bedside. Particularly, evaluation of the dartos reflex provides an indication of the function of the T11-L2 segment that is key for psychogenic arousal and ejaculation [14]. Post SCI, the degree of the ability to perceive pinprick and light touch sensation in T11-L2 is associated with the degree of retention of psychogenic arousal in males and females [4-6, 15]. It is important that this sensation is tested during the neurologic examination and when present to encourage their participation in psychogenic genital arousal. Moreover, in this situation it is important that the patient not work against their sexual responses by ruminating about other concerns as this could cause a negative effect on sexual responses. In order to prevent this, it may be beneficial to encourage mindfulness about sexual responses with SCI patients similar to a program for women with reproductive malignancies [16].

It is also essential to distinguish between UMN and LMN syndromes in the sacral spinal cord as the effect on sexual function differs, thus treatment must be adapted accordingly. Both men and women with UMN lesions affecting the sacral spinal segments have reflex genital arousal. Men with SCI and UMN syndrome are more likely to have reflex erections with projectile ejaculation [2,1719]. They will be more responsive to phosphodiesterase inhibitors for reliable erections [20, 21], and to PVS for ejaculation $[2,22,23]$ than men with LMN syndromes. Orgasm is also more likely to occur and is usually, but not always, associated with ejaculation [7, 24]. By contrast, men with SCI and a LMN syndrome may only have psychogenic erection [2, 17, 18], erectile dysfunction is more difficult to treat [21], and ejaculation is more difficult to trigger with PVS. Orgasm is unlikely in both sexes when there is a complete lesion and no sacral reflexes [5, 7]. Moreover, the fertility potential is reduced compared with other SCI conditions [25]. 
The ISAFSCI provides a mechanism to describe the impact of SCI on sexual responses [8, 10]. In males, the clinician is directed to comment on whether psychogenic or reflex erection remain, and whether ejaculation and orgasm are possible. In females the clinician must comment on psychogenic and reflex lubrication, orgasm potential and the menses. Scores of intact, diminished and absent are used, similar to the ISNCSCI. The use of the ISAFSCI is beneficial because the importance of sexuality can often be diminished when considering other clinical concerns.

An issue with regards to the ISAFSCI comes up when considering these cases. It is clear from these cases that the current version of the ISAFSCI can change based upon other concerns aside from SCI. Therefore, in order to improve the utility of the ISAFSCI standards we recommend that the standards are clarified and should only be used to document the impact of SCI on sexual responses. If the ISAFSCI is used solely to document the potential impact of a person's SCI on sexual responses-as opposed to the current recommendation to use patient self-report the clinician can see if there is a difference between anticipated and perceived report sexual function. Then, if there is a difference, the clinician would realize the need to search for and remediate other potential sources of sexual dysfunction unrelated to the SCI (i.e., medications or perimenopausal changes) as well as other organic problems. These dynamic changes are most appropriately addressed in the Basic Male and Female Sexual Function Data Sets [26] which are designed for active recording of changes in patients ongoing clinical status.

\section{Limitations}

This paper aims to specifically describe the impact of SCI on sexual function through the use of ISAFSCI. While sensation of menses is a component of the ISAFSCI, we did not address this particular issue in these cases. Further information regarding the menses will be available in an upcoming female reproductive data set. Additionally, other papers in Spinal Cord Series and Cases' online collection will present other aspects of the ISAFSCI, hence, we did not detail or use the complete ISAFSCI.

\section{Compliance with ethical standards}

Conflict of interest The authors declare that they have no competing interests.

\section{References}

1. Biering-Sørensen F, Alexander MS, Elliott S, Popolo GD, Previnaire JG, Velez AR. Sexuality and fertility management.
In: Chhabra HS, editor. ISCoS text book on comprehensive management of spinal cord injuries. India: Wolters Kluwer; 2015. p. 613-35.

2. Biering-Sorensen F, Sonksen J. Sexual function in spinal cord lesioned men. Spinal Cord. 2001;39:455-70.

3. Everaert K, de Waard WI, Van Hoof T, Kiekens C, Mulliez T, D'Herde C. Neuroanatomy and neurophysiology related to sexual dysfunction in male neurogenic patients with lesions to the spinal cord or peripheral nerves. Spinal Cord. 2010;48:182-91.

4. Sipski M, Alexander C, Gomez-Marin O, Spalding J. The effects of spinal cord injury on psychogenic sexual arousal in males. $\mathrm{J}$ Urol. 2007;177:247-51.

5. Sipski ML, Alexander CJ, Rosen R. Sexual arousal and orgasm in women: effects of spinal cord injury. Ann Neurol. 2001;49:35-44.

6. Sipski ML, Alexander CJ, Rosen RC. Physiologic parameters associated with sexual arousal in women with incomplete spinal cord injuries. Arch Phys Med Rehabil. 1997;78:305-13.

7. Sipski M, Alexander CJ, Gomez-Marin O. Effects of level and degree of spinal cord injury on male orgasm. Spinal Cord. 2006;44:798-804.

8. Alexander MS, Biering-Sorensen F, Bodner D, Brackett NL, Cardenas D, Charlifue S, et al. International standards to document remaining autonomic function after spinal cord injury. Spinal Cord. 2009;47:36-43.

9. Kirshblum SC, Burns SP, Biering-Sorensen F, Donovan W, Graves DE, Jha A, et al. International standards for neurological classification of spinal cord injury (revised 2011). J Spinal Cord Med. 2011;34:535-46.

10. Krassioukov A, Biering-Sorensen F, Donovan W, Kennelly M, Kirshblum S, Krogh K, et al. International standards to document remaining autonomic function after spinal cord injury. J Spinal Cord Med 2012;35:201-10.

11. Previnaire JG, Soler JM. Physiopathologie des troubles sexuels chez le blessé médullaire. Louvain Medical 2005;124: S280-4.

12. Berger MJ, Kimpinski K, Currie KD, Nouraei H, Sadeghi M, Krassioukov AV. Multi-domain assessment of autonomic function in spinal cord injury using a modified autonomic reflex screen. $\mathrm{J}$ Neurotrauma. 2017; 34:2624-33.

13. Previnaire JG, Soler JM, Leclercq V, Denys P. Severity of autonomic dysfunction in patients with complete spinal cord injury. Clin Auton Res 2012;22:9-15.

14. Soler JM, Previnaire JG. Dartos reflex as autonomic assessment in persons with spinal cord injury. Spinal Cord Ser Cases. 2017. https://doi.org/10.1038/s41394-017-0024-9.

15. Sipski ML, Alexander CJ. Documentation of the impact of spinal cord injury on female sexual function: the female spinal sexual function classification. Top Spinal Cord Inj Rehabil. 2002;8:63-73

16. Brotto LA, Chivers ML, Millman RD, Albert A. Mindfulnessbased sex therapy improves genital-subjective arousal concordance in women with sexual desire/arousal difficulties. Arch Sex Behav. 2016;45:1907-21.

17. Bors EH, Comarr AE. Neurological disturbances of sexual function with special reference to 529 patients with spinal cord injury. Urol Surv. 1960;110:191-222.

18. Comarr AE. Sexual function among patients with spinal cord injury. Urol Int. 1970;25:134-68.

19. Schmid DM, Hauri D, Schurch B. Nocturnal penile tumescence and rigidity (NPTR) findings in spinal cord injured men with erectile dysfunction. Int J Impot Res. 2004;16:433-40.

20. Khorrami MH, Javid A, Moshtaghi D, Nourimahdavi K, Mortazavi A, Zia HR. Sildenafil efficacy in erectile dysfunction secondary to spinal cord injury depends on the level of cord injuries. Int J Androl. 2010;33:861-4. 
21. Soler JM, Previnaire JG, Denys P, Chartier-Kastler E. Phosphodiesterase inhibitors in the treatment of erectile dysfunction in spinal cord-injured men. Spinal Cord. 2007;45:169-73.

22. Chehensse C, Bahrami S, Denys P, Clement P, Bernabe J, Giuliano F. The spinal control of ejaculation revisited: a systematic review and meta-analysis of anejaculation in spinal cord injured patients. Hum Reprod Update. 2013;19:507-26.

23. Soler JM, Previnaire JG, Plante P, Denys P, Chartier-Kastler E. Midodrine improves ejaculation in spinal cord injured men. $\mathrm{J}$ Urol. 2007;178:2082-6.
24. Soler JM, Previnaire JG, Plante P, Denys P, Chartier-Kastler E. Midodrine improves orgasm in spinal cord-injured men: the effects of autonomic stimulation. J Sex Med. 2008;5:2935-41.

25. Hadiji N, Mieusset R, Previnaire JG, Castel-Lacanal E, Soler JM. Ejaculation and sperm characteristics in men with cauda equina and conus medullaris syndromes. Spinal Cord. 2017;55:612-7.

26. Alexander MS, New PW, Biering-Sorensen F, Courtois F, Popolo GD, Elliott S, et al International spinal cord injury male sexual function and female sexual and reproductive function basic data sets-version 2.0. Spinal Cord Ser Cases. 2017;3:17050.

\section{Affiliations}

\section{J.G. Previnaire ${ }^{1} \cdot$ J.M. Soler ${ }^{2}$ M.S. Alexander ${ }^{3,4,5} \cdot$ F. Courtois ${ }^{6} \cdot$ S. Elliott $^{7} \cdot$ A. McLain $^{3}$}

1 Spinal Unit, Centre Calve, Fondation Hopale, 62600 Berck-sur-Mer, France

2 Centre Bouffard Vercelli, 66290 Cerbere, France

3 Department of Physical Medicine and Rehabilitation University of Alabama at Birmingham School of Medicine Birmingham, Birmingham, AL, USA

4 Birmingham VA Medical Center Birmingham, Birmingham, AL, USA
5 Department of Physical Medicine and Rehabilitation Harvard School of Medicine Boston, Boston, MA, USA

6 Departement of Sexology, Université du Québec à Montréal, Montréal, QC, CanadaH2L 2C4

7 Department of Psychiatry and Urologic Sciences \& ICORD, University of British Columbia, Vancouver, BC, Canada 